\title{
openheart Prevalence and determinants of hypertension control among almost 100000 treated adults in the UK
}

\author{
Neo Tapela (D ) , ${ }^{1,2}$ Jennifer Collister, ${ }^{1}$ Lei Clifton, ${ }^{1}$ Iain Turnbull, ${ }^{1}$ Kazem Rahimi, ${ }^{3}$ \\ David J Hunter ${ }^{1}$
}

\begin{abstract}
- Prepublication history and additional material is published online only. To view please visit the journal online (http://dx.doi. org/10.1136/openhrt-2020001461).
\end{abstract}

To cite: Tapela N, Collister J, Clifton L, et al. Prevalence and determinants of hypertension control among almost 100000 treated adults in the UK. Open Heart 2021;8:e001461.

doi:10.1136/

openhrt-2020-00146

Received 1 October 2020 Revised 8 December 2020 Accepted 21 December 2020

Check for updates

C Author(s) (or their employer(s)) 2021. Re-use permitted under CC BY. Published by BMJ.

${ }^{1}$ Nuffield Department of Population Health, University of Oxford, Oxford, UK

${ }^{2}$ Botswana-Harvard AIDS Institute Partnership, Gaborone, Botswana

${ }^{3}$ Deep Medicine, Nuffield Department of Reproductive and Women's Health, University of Oxford, Oxford, UK

Correspondence to Dr Neo Tapela; ntapela@gmail. com

\section{ABSTRACT}

Objective To identify factors associated with hypertension control among treated middle-aged UK adults.

Methods A cross-sectional population-based study including 99468 previously diagnosed, treated hypertensives enrolled in the UK Biobank. Hypertension control was defined as systolic blood pressure $<140 \mathrm{~mm}$ $\mathrm{Hg}$ and diastolic blood pressure $<90 \mathrm{~mm} \mathrm{Hg}$.

Results Median age was 62.3 years (IQR 57.3 to 66.0 ), $45.9 \%$ female, $92.0 \%$ white, $40.1 \%$ obese, $9.3 \%$ current smokers and $19.4 \%$ had prior cardiovascular disease. $38.1 \%$ (95\% Cl $37.8 \%$ to $38.4 \%$ ) were controlled. In multivariable logistic regression, associations with lack of hypertension control included: older age (OR 0.61, $95 \% \mathrm{Cl} 0.58$ to 0.64 for $60-69$ years compared with age 40-50 years), higher alcohol use (OR 0.61, 95\% $\mathrm{Cl} 0.58$ to 0.64 , for consuming $>30$ units per week compared with none), black ethnicity (OR $0.73,95 \% \mathrm{Cl}$ 0.65 to 0.82 compared with white), obesity (OR 0.73 , $95 \% \mathrm{Cl} 0.71$ to 0.76 compared with normal body mass index). The strongest positive association with control was having $\geq 3$ comorbidities (OR $2.09,95 \% \mathrm{Cl} 1.95$ to 2.23). Comorbidities associated with control included cardiovascular disease (OR 2.11, 95\% CI 2.04 to 2.19), migraines (OR 1.68, 95\% Cl 1.56 to 1.81), diabetes (OR $1.32,95 \% \mathrm{Cl} 1.27$ to 1.36 ) and depression (OR 1.27, 95\% $\mathrm{Cl} 1.20$ to 1.34 ).

Conclusions In one of the largest population-based analyses of middle-aged adults with measured blood pressure, the majority of treated hypertensives were uncontrolled. Risk factors for hypertension were associated with a lower probability of control. Having a comorbidity was associated with higher probability of control, possibly due to more frequent interaction with the healthcare system and/or appropriate management of those at greater cardiovascular risk.

\section{INTRODUCTION}

Hypertension is the leading preventable risk factor for cardiovascular disease (CVD) mortality, affecting over 1.3 billion people around the world ${ }^{1}$ and responsible for approximately half of all strokes and ischaemic cardiac events. ${ }^{2}$ Clinical trials have demonstrated that lowering blood pressure (BP) reduces the incidence of stroke by $35 \%-40 \%$,

\section{Key questions}

What is already known about this subject?

- Hypertension is prevalent in middle-aged adults in high-income countries. Factors influencing hypertension control in this population may differ from those in younger adults, and studies have been mixed on the association between comorbidities and hypertension control.

What does this study add?

- Our study is one of the largest population-based analyses of middle-aged adults treated for hypertension. Our findings suggest high levels of uncontrolled hypertension and identify characteristics associated with lower probability of hypertension control. Our findings may inform further investigations needed to better understand barriers to hypertension control, and contribute to the limited evidence on the association between comorbidities and hypertension control.

How might this impact on clinical practice?

- Our findings may help to identify subgroups for which clinical practice improvement efforts can be targeted.

myocardial infarction by $20 \%-25 \%$ and heart failure by $50 \%{ }^{3}$ Despite this, and the availability of low-cost treatments for hypertension, ${ }^{4}$ many hypertensives are undiagnosed or inadequately treated. ${ }^{4-6}$ More evidence on factors influencing hypertension control is needed to support the efforts of clinicians and policymakers to reduce the CVD burden.

Previous studies have reported on factors associated with hypertension control in the general adult population in the UK. ${ }^{7}$ Determinants of hypertension control may differ between younger and older adults. ${ }^{8}$ Better understanding of the factors associated with hypertension control is particularly needed for middle-aged and older adults, for whom hypertension is more prevalent but achieving control may be more challenging. ${ }^{9}$ Comorbidities and multimorbidity may be 
important factors influencing hypertension control in older people. ${ }^{7}$ Multimorbidity is defined as the concurrent presence of two or more long-term conditions, ${ }^{10}$ and is of increasing public health concern globally given its rising prevalence in the context of longer life expectancy and higher disease-specific survival rates. Multimorbidity has been associated with higher health service utilisation, social deprivation and increased mortality. ${ }^{10}$ However, multimorbidity is relatively understudied, and the existing studies have focused on the prevalence or clustering of multimorbidity or its impact on general health outcomes. ${ }^{10-12}$ The few studies investigating the relationship of multimorbidity with hypertension control have been inconsistent in their findings, particularly whether non-cardiovascular comorbidities are associated with better hypertension control. ${ }^{713}$

We aimed to: (1) determine the prevalence of hypertension control among UK adults aged 40-69 years old previously diagnosed with hypertension and currently on antihypertensive treatment and (2) identify factors associated with hypertension control (primary objective), including whether multimorbidity and specific comorbidities were associated with hypertension control.

\section{METHODS}

\section{Design and study population}

We analysed baseline survey data from the UK Biobank (UKB), a large population-based prospective cohort study that recruited via mail 500000 adults aged 40-69 years residing within $40 \mathrm{~km}$ of 22 assessment centres across England, Scotland and Wales between 2006 and $2010 .^{14}$ Participation required presenting to the assessment centres and providing written informed consent. Participants who had completed the baseline survey, and reported previously being informed by a health professional that they had hypertension (aware), and reported use of antihypertensive medications (treated) were included in this analysis. We specified exclusion criteria a priori and excluded participants who were pregnant, had fewer than two BP measurements at the baseline visit or had implausible BP values (defined as previously reported $^{15}$ : systolic BP $<70 \mathrm{~mm} \mathrm{Hg}$ or $\geq 270 \mathrm{~mm} \mathrm{Hg}$, diastolic BP $<50 \mathrm{~mm} \mathrm{Hg}$ or $\geq 150 \mathrm{~mm} \mathrm{Hg}$ ). We additionally excluded participants who had a medical history notable for a condition: associated with poor prognosis (kidney failure, heart failure, liver failure, cancer other than skin); or for which the goals of care might take priority over hypertension control (eg, suicide attempt); or for which the participant may have required additional support from a caretaker for hypertension management, acknowledging that the UKB database did not include measures of severity of these conditions (schizophrenia, dementia, Parkinson's disease, multiple sclerosis, myasthenia gravis, motor neuron disease, other demyelinating disease).

\section{Procedures and definitions}

The UKB baseline information was gathered through (1) a self-administered computer touch screen structured questionnaire at survey centres, followed by (2) same-day in-person structured interview by a trained nurse, which was then followed by (3) physical measurements by a trained nurse (BP, weight, waist circumference). The in-person interview was coupled with review of the participant's medication list, which participants had been asked to bring with them (over $80 \%$ of UKB participants complied). The survey collected information on sociodemographic characteristics, lifestyle health-related behaviour, medical history, family history of CVD and previous health screenings. BP measurement was performed twice, $1 \mathrm{~min}$ apart, with the participant in a sitting position and using an Omron HEM 7015-T automated sphygmomanometer. Participants with elevated BP (or other abnormal findings) were provided with a print-out of their results and advised to follow-up with their general practitioner.

Hypertension control was defined as having a mean systolic $\mathrm{BP}<140 \mathrm{~mm} \mathrm{Hg}$ and diastolic $\mathrm{BP}<90 \mathrm{~mm} \mathrm{Hg}$, among individuals who reported previously being informed of a hypertension diagnosis by a health professional (aware) as well as use of antihypertensives (treated). The BP treatment target used is consistent with the UK National Institute for Health and Care Excellence (NICE) guidelines for hypertension management during the study period (NICE 2006) and other guidelines such as the United States' seventh Report of the Joint National Committee on High BP, WHO-International Society of Hypertension and the European Society of Hypertension. ${ }^{16}$

Reported use of antihypertensives was via either one of two means. First, selection of 'BP medication' in response to the touchscreen question 'Do you regularly take any of the following medications?' Second, report during the interview of use of medications that are antihypertensives and which were subsequently assessed to be "probably for hypertension indication' based on an antihypertensive treatment rubric we developed. This rubric was based on the NICE 2006 guidelines and employed the Anatomical Therapeutic Chemical classification system, ${ }^{17}$ which has been endorsed by the WHO and has been similarly applied in a previous UKB publication. ${ }^{18}$ In applying this rubric, we classified hypertensives as on antihypertensives 'probably for hypertension indication' if they were on medications in the first to fourth lines of treatment in 2006 NICE clinical algorithm, but did not report a diagnosis that was an alternate indication for the medications (eg, diabetes for ACE inhibitors).

Variables that were included in the analyses were sociodemographic characteristics, known or possible determinants of CVD (alcohol intake, smoking, physical activity, body mass index (BMI)) or hypertension control (number of comorbidities, types of comorbidities, number of antihypertensive medications, prior colorectal cancer 
screening as a proxy for healthcare utilisation). BMI was calculated by dividing weight by height squared $\left(\mathrm{kg} / \mathrm{m}^{2}\right)$ and categorised as: underweight $<18.5 \mathrm{~kg} / \mathrm{m}^{2}$, normal $18.5-24.9 \mathrm{~kg} / \mathrm{m}^{2}$, overweight $25.0-29.9 \mathrm{~kg} / \mathrm{m}^{2}$ and obese $\geq 30.0 \mathrm{~kg} / \mathrm{m}^{2}$. Standard alcohol units (alcohol by volume equivalents) were derived from participant responses of the number of typical volume drinks for each type of alcohol consumed per week (eg, pint of beer, glass of wine, measure/shot of spirits/liquors). Physical activity was assessed using adapted questions from the validated short International Physical Activity Questionnaire ${ }^{19}$; the time spent in vigorous, moderate and walking activity was weighted by the energy expended for these categories of activity, to produce total metabolic equivalent task minutes per week. The Townsend deprivation index, based on the geographic unit of census output areas, is a measure of socioeconomic material deprivation that combines four variables routinely available in census data (unemployment, non-ownership of a car, non-ownership of a home and overcrowding at home) and strongly correlates with mortality. ${ }^{20}$ Education categories followed the scales used in the International Standard Classification of Education, while occupation categories followed the UK Office of National Statistics' Standard Occupational Classification system.

In selecting comorbidities to be analysed, we took into consideration the prevalence of each condition in the middle-aged population of the UK, its clinical significance, as well as its inclusion in previous multimorbidity studies ${ }^{12} 21$ and the UK's Quality Outcomes Framework-a pay-for-performance scheme to incentivise quality care by general practitioners. Conditions thus selected spanned cardiometabolic, respiratory, psychiatric and neurological systems. CVD was defined as ischaemic heart disease, stroke or transient ischaemic attack.

\section{Statistical analysis}

Descriptive analyses were performed to compute the proportion of hypertension control, overall and stratified. Logistic regression models were fitted to compute unadjusted, age-adjusted and sex-adjusted and multiplyadjusted ORs and 95\% CIs of explanatory variables. Sensitivity analysis was performed using only the second BP measurement (which tended to be lower than the first measurement). Exploratory analyses were performed to interrogate potential explanations for the results, the impact of excluding those with serious comorbidities, and effect modification by age group, number of comorbidities and presence of prior CVD. Agreement of BP measurements over time was assessed using Spearman correlation coefficients, for all UKB participants who had repeat BP measured within 3 years of the baseline visit (n 2134 , or $0.4 \%$ of all UKB participants). All analyses were performed using R V.3.6.2. ${ }^{22}$
RESULTS

\section{Participant characteristics}

Out of 502506 enrolled UKB participants, 99468 were previously treated hypertensives who met inclusion and exclusion criteria for this analysis (figure 1). The median age in this group was 62.3 years (IQR 57.3-66.0 years), with $45.9 \%(45607)$ of them female, $92.9 \%$ (92 385) white and $25.7 \%$ (25 606) having primary school as their highest attained education (table 1$)$. A fifth $(19.4 \% ; 19$ 344) reported previous diagnosis of CVD, $40.1 \%$ (39 887) were obese and $9.3 \%$ (9254) were current smokers. The median duration of hypertension diagnosis was 7.3 years (IQR 3.6-12.6 years); $13.9 \%$ of all treated hypertensives were on $\geq 3$ antihypertensives. Among the 19344 treated hypertensives with CVD, $19.3 \%$ (3740) were on $\geq 3$ antihypertensives; among the 79022 treated hypertensives without CVD who were not smokers and were not obese (lower risk), $12.5 \%$ (9886) were on $\geq 3$ antihypertensives (online supplemental table 1).

\section{Prevalence of hypertension control}

Among all individuals aged 40-69year including in this analysis $(459,484)$, we found a hypertension prevalence of $55.8 \%$ (95\% CI 55.6\% to 55.9\%; 256203 ), as well as notable gaps in the hypertension care cascade (figure 1). Nearly half $(46.9 \%, 95 \%$ CI $46.7 \%$ to $47.1 \%$; 120211$)$ of hypertensives were unaware of their condition; $26.9 \%$ (95\% CI 26.6\% to $27.1 \%$; 36 524) of those who were aware were untreated; only $38.1 \%$ (95\% CI $37.8 \%$ to $38.4 \%$; 37 925) of treated hypertensives were controlled (61543 or $61.9 \%$ were suboptimally treated). When employing a more conservative threshold of $\mathrm{BP}<160 / 100 \mathrm{~mm} \mathrm{Hg}$ to define hypertension control, we found that 20573 or $20.7 \%$ (95\% CI $20.4 \%$ to $20.9 \%$ ) were suboptimally treated (online supplemental figure 1). In fact, 3.8\% (3754) of treated hypertensives had a systolic BP $\geq 180$ or diastolic $\mathrm{BP} \geq 110 \mathrm{~mm} \mathrm{Hg}$ (online supplemental figure 2).

Regression to the mean, random within-person variation, white coat hypertension and changes in lifestyle or medications notwithstanding, our analysis indicates good concordance over time (Spearman's rank correlations of 0.72 for systolic BP and 0.70 for diastolic BP for repeat measurements within 3 years) and high probability ( $73.1 \%$ agreement) that those classified as hypertensive at baseline using the $140 / 90 \mathrm{~mm} \mathrm{Hg}$ threshold would have been classified similarly with a follow-up BP measurement (online supplemental table 2).

\section{Factors associated with hypertension control}

Hypertension control was inversely associated with known risk factors of hypertension: older age (multiplyadjusted OR $0.61,95 \%$ CI 0.58 to 0.64 for age $60-69$ years compared with reference age group 40-49year olds), male gender (OR $0.92,95 \%$ CI 0.89 to 0.95 ), higher alcohol use (OR $0.61,95 \%$ CI 0.58 to 0.64 for consumption of over 30 units per week), black ethnicity (OR 0.73 , 


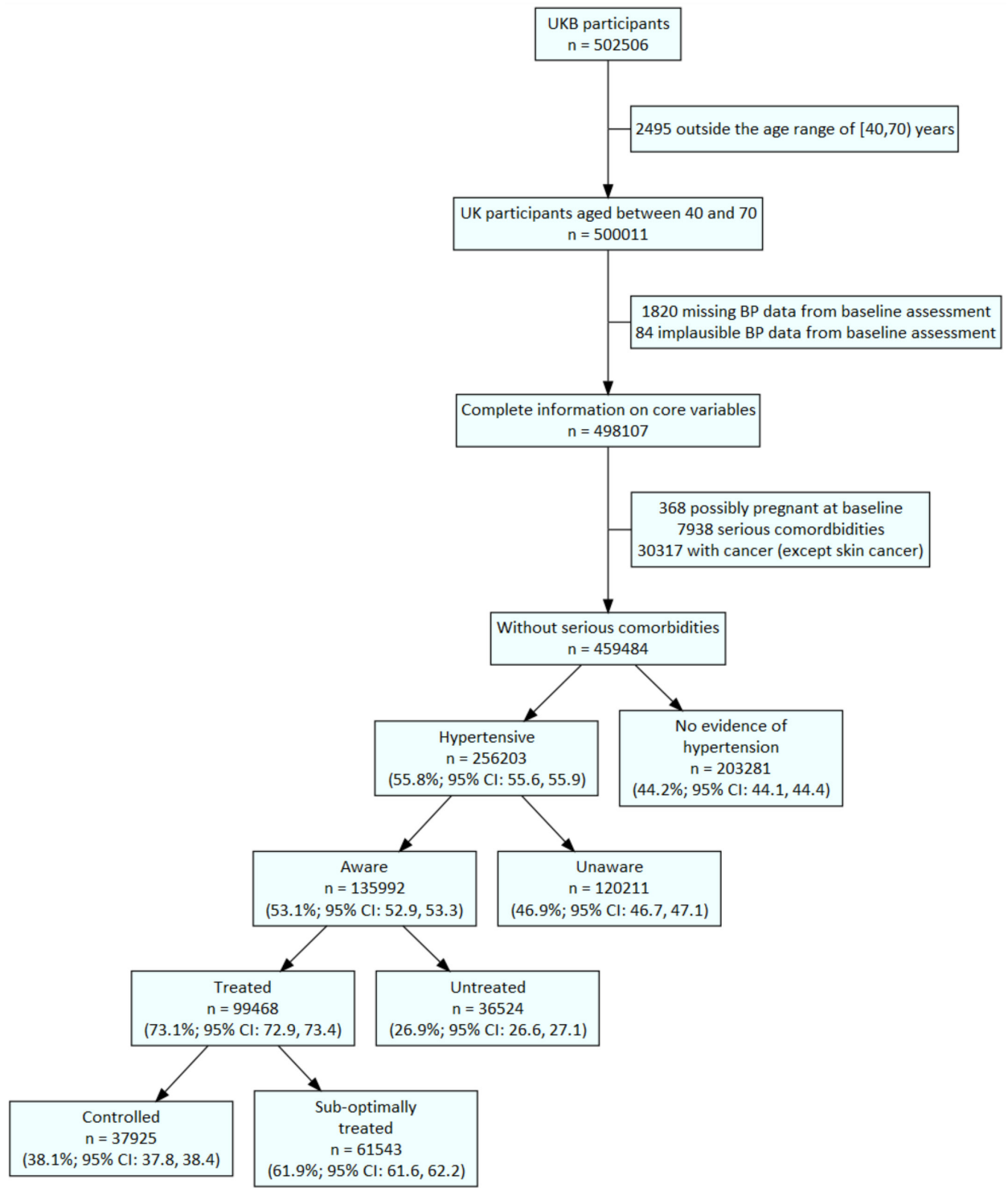

Figure 1 Flow chart illustrating selection of analytical dataset (n 99 468). Missing BP data comprises: having fewer than two BP measurements at baseline assessment or missing responses to questions on hypertension history. The following BP values were deemed implausible (defined as previously reported (15): systolic BP $<70 \mathrm{~mm} \mathrm{Hg}$ or $\geq 270 \mathrm{~mm} \mathrm{Hg}$, diastolic BP $<50 \mathrm{~mm}$ $\mathrm{Hg}$ or $\geq 150 \mathrm{~mm} \mathrm{Hg}$. Hypertension was defined as self-report of hypertensive medication use, or self-report of a prior diagnosis of hypertension, or mean BP $\geq 140 / 90 \mathrm{~mm} \mathrm{Hg}$ at baseline assessment. Awareness was defined as report of a prior diagnosis of hypertension by a health professional, among those who were hypertensive. Treatment was defined as report of hypertensive medication among those who were aware. Control was defined as mean BP $<140 / 90 \mathrm{~mm} \mathrm{Hg}$ at baseline assessment, among those who were treated. Hypertensives who were aware and treated but had BP $\geq 140 / 90 \mathrm{~mm} \mathrm{Hg}$ were classified as inadequately treated. The BP diagnostic threshold and treatment targets used are consistent with the UK NICE guidelines for hypertension management during the study period (NICE 2006) and other guidelines such as the USA's 7th Report of the Joint National Committee on High BP, WHO-International Society of Hypertension and the European Society of Hypertension. ${ }^{16}$ BP, blood pressure; NICE, National Institute for Health and Care Excellence; UKB, UK Biobank.

95\% CI 0.65 to 0.82 compared with White ethnicity), and obesity (OR $0.73,95 \%$ CI 0.71 to 0.76 ) (table 2 ).

Hypertension control was also inversely associated with characteristics that reflect lower socioeconomic standing, including: low income (OR 0.82, 95\% CI 0.75 to 0.90 for those with an annual household income of $£ 18000$ compared with a reference group of $>£ 100000$ ), low education (OR 0.94, 95\% CI 0.91 to 0.98 for those educated to primary school level only compared with those who reached tertiary level), and less professionalised occupations (OR $0.88,95 \%$ CI 0.83 to 0.93 for manual and industrial occupations compared with professional and senior administrative occupations). Paradoxically, however, individuals who lived in the most materially deprived areas (based on the Townsend index) and those with lower physical activity had higher odds of hypertension control. Residence in Scotland (OR 0.86, 95\% CI 0.82 to 0.91 ) or Wales (OR $0.87,95 \%$ CI 0.82 to 0.93 ) was associated with slightly lower odds of hypertension control compared with residence in England. 
Cardiac risk factors and prevention

Table 1 Characteristics of participants included in the analysis (treated hypertensives, $\mathrm{N}=99$ 468)

\begin{tabular}{|c|c|c|c|}
\hline Variable & $\begin{array}{l}\text { Levels (for } \\
\text { categorical) }\end{array}$ & $\mathbf{n}$ & $\%$ \\
\hline Median age, years (IQR) & & 62.3 & $(57.3-66.0)$ \\
\hline \multirow[t]{3}{*}{ Age group, years } & $40-49$ & 7717 & 7.8 \\
\hline & $50-59$ & 27823 & 28.0 \\
\hline & $60-69$ & 63928 & 64.3 \\
\hline \multirow[t]{2}{*}{ Gender } & Female & 45607 & 45.9 \\
\hline & Male & 53861 & 54.1 \\
\hline \multirow[t]{6}{*}{ Ethnic group } & White & 92385 & 92.9 \\
\hline & Black & 2362 & 2.4 \\
\hline & S.Asian & 2118 & 2.1 \\
\hline & Mixed & 458 & 0.5 \\
\hline & Other & 1641 & 1.6 \\
\hline & Unanswered & 504 & 0.5 \\
\hline \multirow[t]{7}{*}{ Household income, GBP } & Greater than 100000 & 2529 & 2.5 \\
\hline & 52000 to 100000 & 11039 & 11.1 \\
\hline & 31000 to 51999 & 18368 & 18.5 \\
\hline & 18000 to 30999 & 23956 & 24.1 \\
\hline & Less than 18000 & 26443 & 26.6 \\
\hline & Do not know & 5353 & 5.4 \\
\hline & Unanswered & 11780 & 11.8 \\
\hline \multirow[t]{8}{*}{ Occupation category* } & $\begin{array}{l}\text { Professional and } \\
\text { administrative }\end{array}$ & 33464 & 33.6 \\
\hline & Skilled trades & 4232 & 4.3 \\
\hline & Services & 5078 & 5.1 \\
\hline & Manual and industrial & 6443 & 6.5 \\
\hline & Other employment & 3118 & 3.1 \\
\hline & Retired & 37081 & 37.3 \\
\hline & $\begin{array}{l}\text { Unable to work because of } \\
\text { sickness or disability }\end{array}$ & 5304 & 5.3 \\
\hline & Unemployed/unanswered & 4748 & 4.8 \\
\hline \multirow{5}{*}{$\begin{array}{l}\text { Highest level of education } \\
\text { (ISCED) } \dagger\end{array}$} & 5: Tertiary & 38924 & 39.1 \\
\hline & $\begin{array}{l}\text { 4: Post-secondary non- } \\
\text { tertiary }\end{array}$ & 12224 & 12.3 \\
\hline & 2-3: Secondary & 20635 & 20.7 \\
\hline & 1: Primary & 25606 & 25.7 \\
\hline & Unanswered & 2079 & 2.1 \\
\hline \multirow[t]{3}{*}{ UK country of residence $\ddagger$} & England & 88122 & 88.6 \\
\hline & Scotland & 7109 & 7.1 \\
\hline & Wales & 4237 & 4.3 \\
\hline \multirow[t]{5}{*}{ BMI (categorical)§ } & Underweight & 197 & 0.2 \\
\hline & Normal (ref) & 17206 & 17.3 \\
\hline & Overweight & 41574 & 41.8 \\
\hline & Obese & 39887 & 40.1 \\
\hline & Unanswered & 604 & 0.6 \\
\hline \multirow[t]{3}{*}{ Smoking status } & Never & 48974 & 49.2 \\
\hline & Previous & 40595 & 40.8 \\
\hline & Current & 9254 & 9.3 \\
\hline
\end{tabular}

Table 1 Continued

\begin{tabular}{lllr}
\hline Variable & $\begin{array}{l}\text { Levels (for } \\
\text { categorical) }\end{array}$ & $\mathbf{n}$ & $\%$ \\
\hline & Unanswered & 645 & 0.6 \\
$\begin{array}{l}\text { Median reported duration of } \\
\text { hypertension, years (IQR) }\end{array}$ & 1 & 7.3 & $(3.6-12.6)$ \\
$\begin{array}{l}\text { No of antihypertensive } \\
\text { medications }\end{array}$ & 2 & 48501 & 48.8 \\
& $\geq 3$ & 33678 & 33.9 \\
& Medication list unavailable & 3453 & 3.5 \\
\hline Cardiovascular disease & No & 80124 & 80.6 \\
\hline Diabetes & Yes & 19344 & 19.4 \\
\hline No of comorbiditiesף & No & 84040 & 84.5 \\
\hline & Yes & 15428 & 15.5 \\
\hline & 1 & 44968 & 45.2 \\
\hline & 2 & 36901 & 37.1 \\
\hline & $\geq 3$ & 13583 & 13.7 \\
\hline
\end{tabular}

*Occupation categories have been condensed from those recorded in UKB. Professional and administrative: managers and senior officials, professional occupations, associate professional and technical occupations, administrative and secretarial occupations. Skilled trades: skilled trades occupations. Services: personal service occupations, sales and customer service occupations. Manual and industrial: process, pPlant and machine operatives, elementary occupations. Other employment: free text entry that was not coded by UKB.

†Self-reported highest education achieved was mapped to the ISCED categories.

¥The assessment centre the participant attended was used as a proxy for country of residence.

$\S B M I$ has been categorised as: underweight $<18.5 \mathrm{~kg} / \mathrm{m}^{2}$; normal $18.5-24.9 \mathrm{~kg} / \mathrm{m}^{2}$; overweight $25.0-29.9 \mathrm{~kg} / \mathrm{m}^{2}$; obese $\geq 30.0 \mathrm{~kg} / \mathrm{m}^{2}$. IThe conditions that counted towards the number of comorbidities were: cardiovascular disease, diabetes, arrhythmia (afib/flutter), asthma or COPD, migraines, epilepsy, anxiety, depression, osteoarthritis, other joint disorder.

$\mathrm{BMI}$, body mass index; COPD, chronic obstructive pulmonary disease; ISCED, International Standard Classification of Education; UKB, UK Biobank.

Smoking, a CVD risk factor, was associated with higher odds of hypertension control (OR 1.24, 95\% CI 1.19 to 1.30 for current smokers compared with those who had never smoked). The characteristic most strongly associated with hypertension control was having $\geq 3$ comorbidities (OR 2.09, 95\% CI 1.95 to 2.23; table 2). When considering the individual comorbidities (table 3 ), those most strongly associated with hypertension control were known CVD (OR 2.11, 95\% CI 2.04 to 2.19), atrial fibrillation or atrial flutter (OR 1.72, 95\% CI 1.56 to 1.90), migraines (OR $1.68,95 \%$ CI 1.56 to 1.81 ), anxiety (OR $1.47,95 \%$ CI 1.34 to 1.62 ), diabetes (OR $1.32,95 \%$ CI 1.27 to 1.36 ) and depression (OR 1.27, 95\% CI 1.20 to $1.34)$.

Results from analyses using the second BP measurement alone, stratified by 10-year age groups (given that the majority of UKB participants were 60-69 years old), stratified by the number of comorbidities and CVD status 


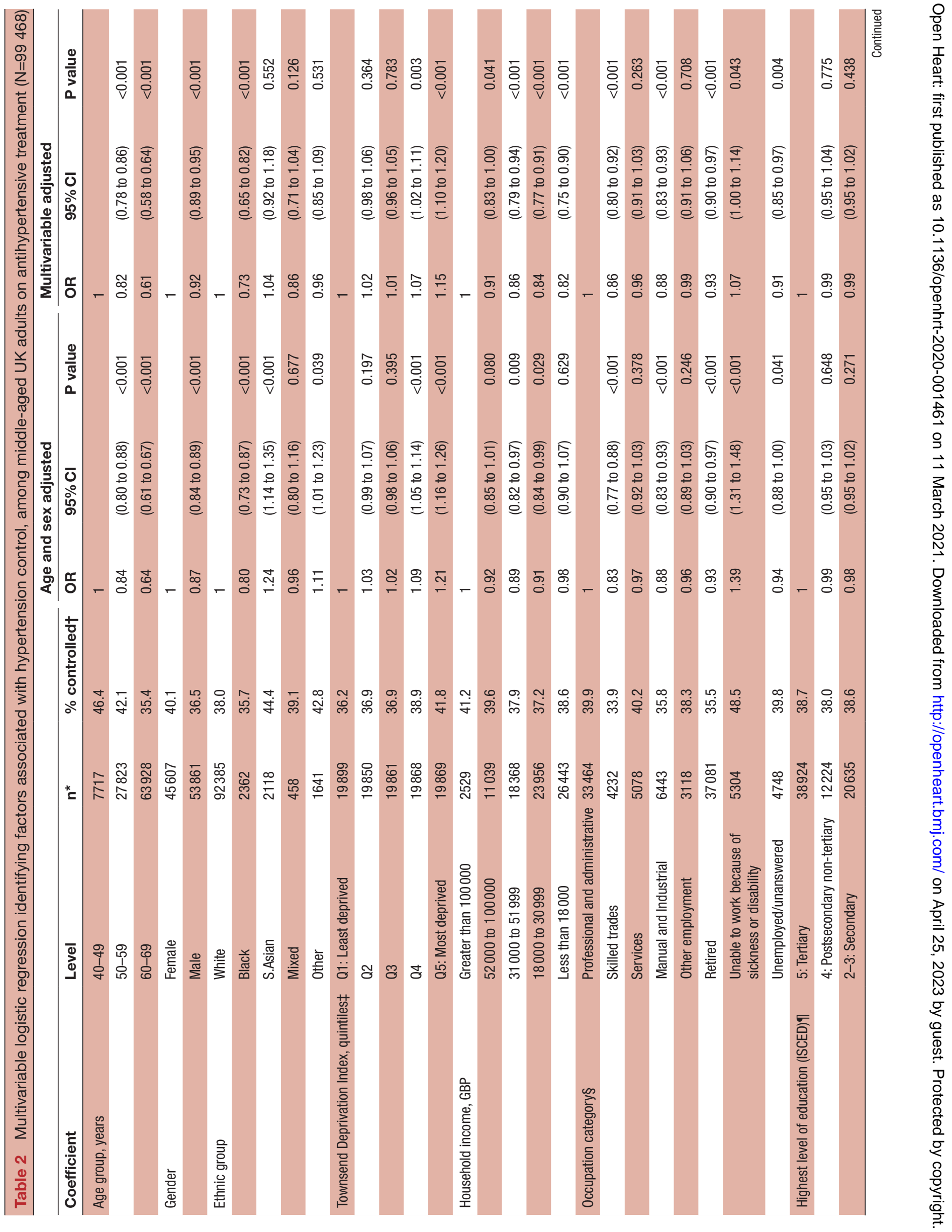




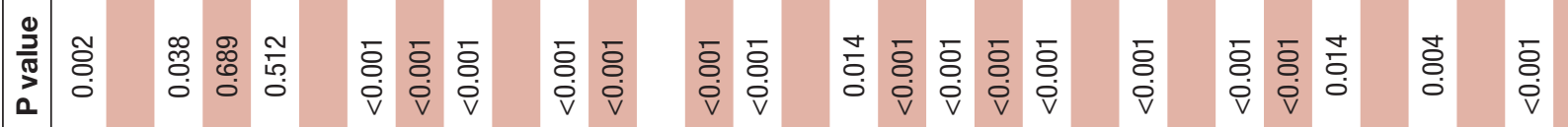

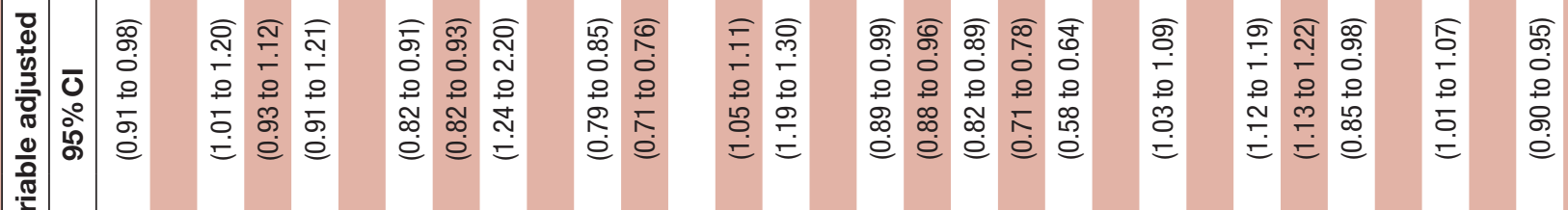

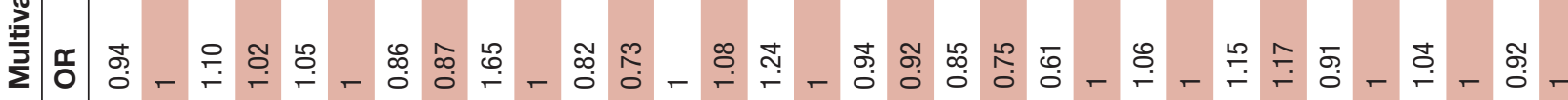

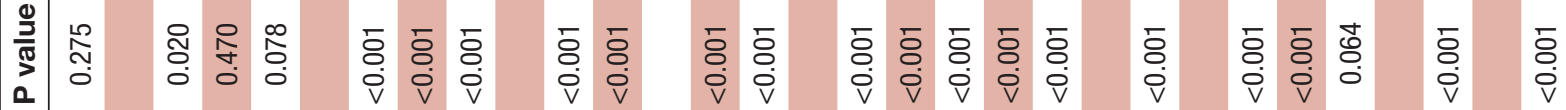

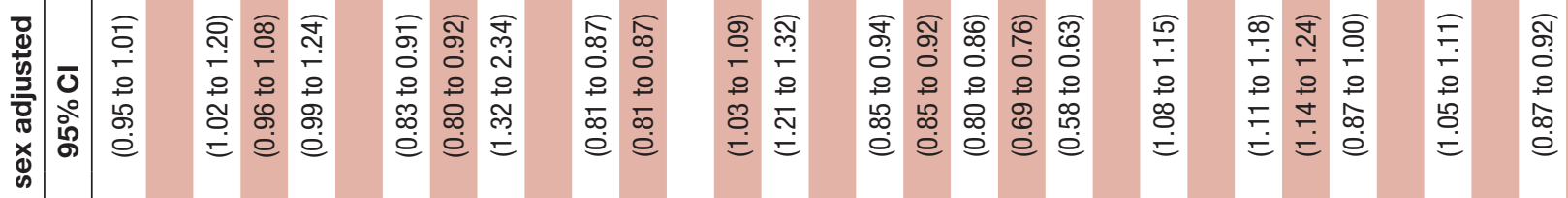

突

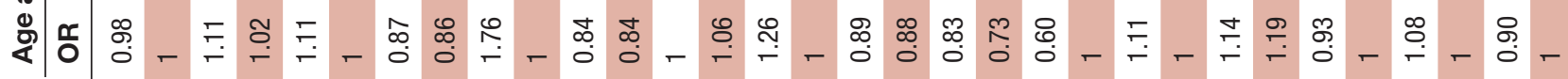

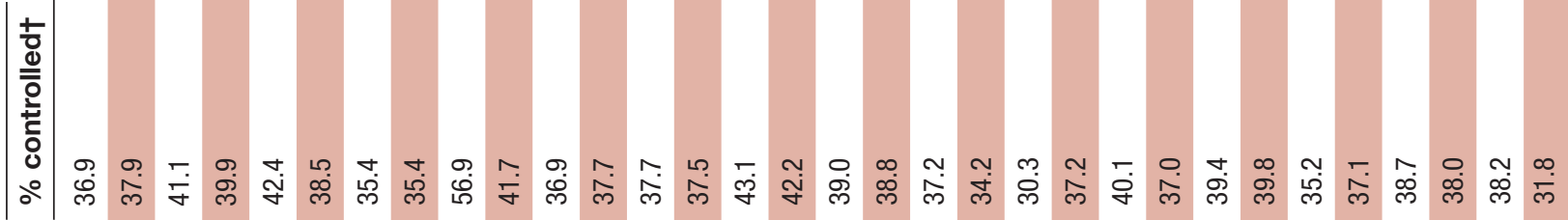

*
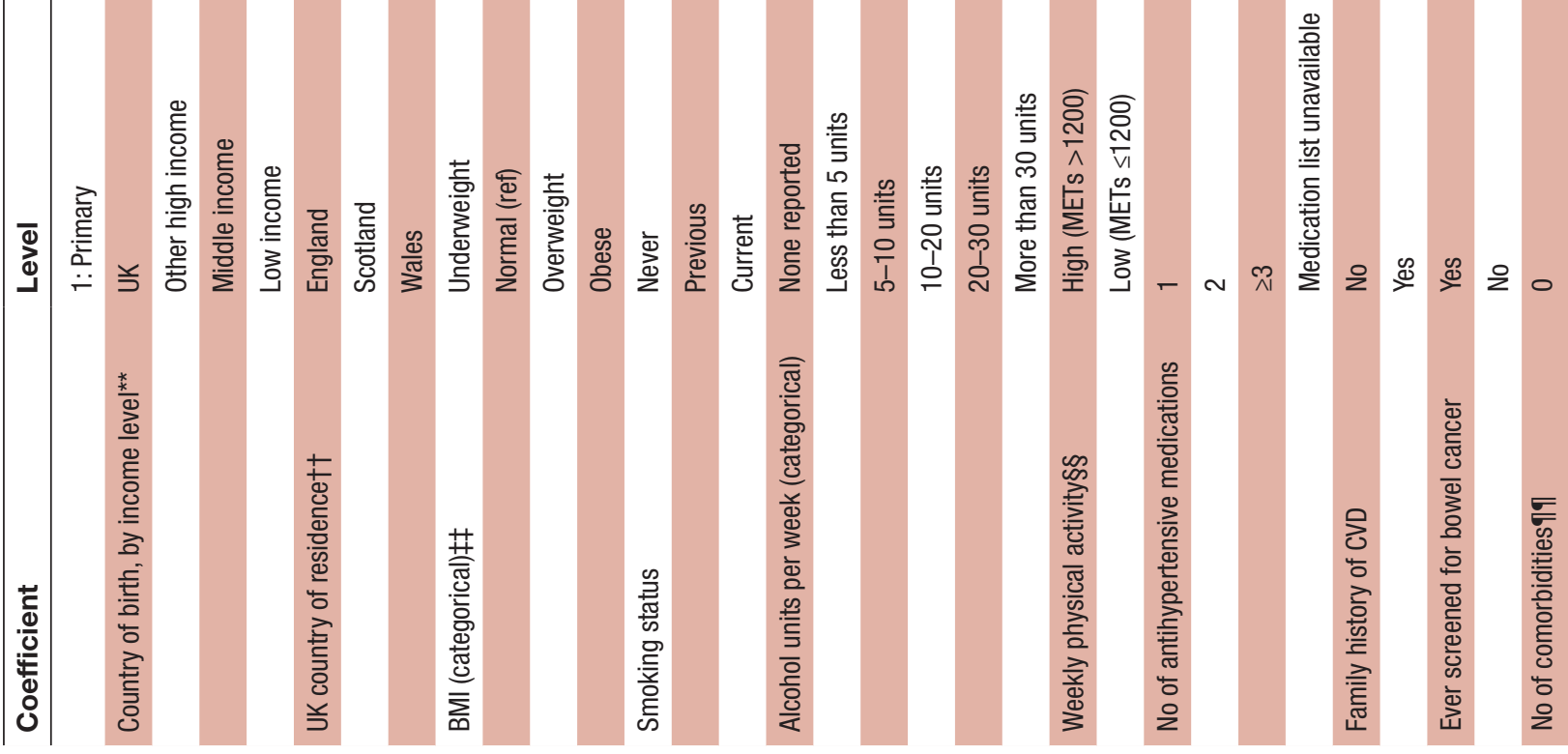


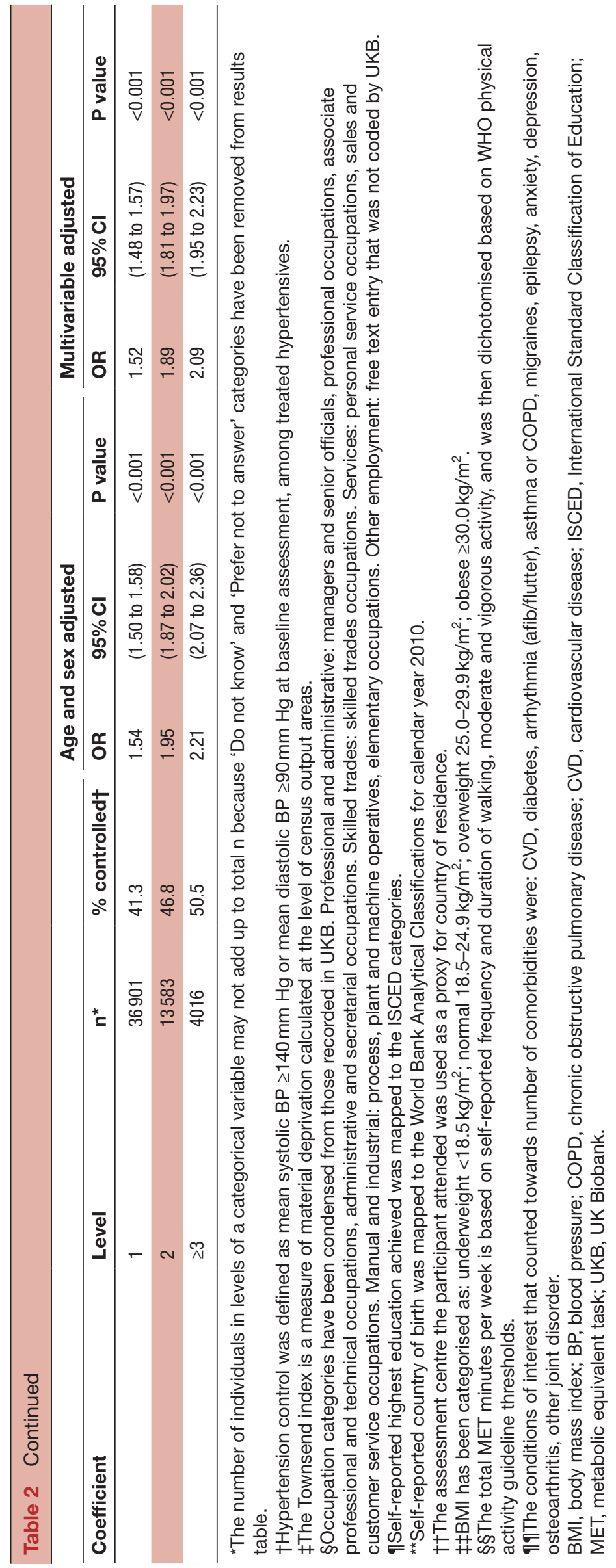


Table 3 Multivariable logistic regression examining the association of individual comorbidities with hypertension control, among middle-aged UK adults on anti-hypertensive treatment ( $N=99468)$

\begin{tabular}{|c|c|c|c|c|c|c|c|c|c|}
\hline \multirow[b]{2}{*}{ Coefficient } & \multirow[b]{2}{*}{ Level } & \multirow[b]{2}{*}{$\mathbf{n}$} & \multirow[b]{2}{*}{$\begin{array}{l}\% \\
\text { controlled† }\end{array}$} & \multicolumn{3}{|c|}{ Age and sex adjusted } & \multicolumn{3}{|c|}{ Multivariable adjusted* } \\
\hline & & & & OR & $95 \% \mathrm{Cl}$ & $P$ value & OR & $95 \% \mathrm{Cl}$ & $P$ value \\
\hline \multirow[t]{2}{*}{ CVD } & No & 80124 & 34.9 & 1 & & & 1 & & \\
\hline & Yes & 19344 & 51.3 & 2.20 & (2.12 to 2.27 ) & $<0.001$ & 2.11 & (2.04 to 2.19 ) & $<0.001$ \\
\hline \multirow[t]{2}{*}{ Diabetes } & No & 84040 & 37.1 & 1 & & & 1 & & \\
\hline & Yes & 15428 & 43.9 & 1.36 & (1.31 to 1.41 ) & $<0.001$ & 1.32 & (1.27 to 1.36$)$ & $<0.001$ \\
\hline \multirow[t]{2}{*}{ Arrhythmia (afib/flutter) } & No & 97769 & 37.9 & 1 & & & 1 & & \\
\hline & Yes & 1699 & 49.0 & 1.70 & (1.55 to 1.87 ) & $<0.001$ & 1.72 & (1.56 to 1.90$)$ & $<0.001$ \\
\hline \multirow[t]{2}{*}{ Asthma or COPD } & No & 86889 & 38.0 & 1 & & & 1 & & \\
\hline & Yes & 12579 & 38.8 & 1.01 & (0.97 to 1.05$)$ & 0.650 & 0.96 & (0.92 to 1.00$)$ & 0.031 \\
\hline \multirow[t]{2}{*}{ Migraines } & No & 96500 & 37.7 & 1 & & & 1 & & \\
\hline & Yes & 2968 & 52.7 & 1.68 & (1.56 to 1.81 ) & $<0.001$ & 1.68 & (1.56 to 1.81$)$ & $<0.001$ \\
\hline \multirow[t]{2}{*}{ Epilepsy } & No & 98631 & 38.1 & 1 & & & 1 & & \\
\hline & Yes & 837 & 41.3 & 1.10 & (0.96 to 1.26$)$ & 0.178 & 0.96 & (0.83 to 1.10$)$ & 0.554 \\
\hline \multirow[t]{2}{*}{ Anxiety } & No & 97564 & 37.9 & 1 & & & 1 & & \\
\hline & Yes & 1904 & 49.7 & 1.51 & (1.38 to 1.66$)$ & $<0.001$ & 1.47 & (1.34 to 1.62$)$ & $<0.001$ \\
\hline \multirow[t]{2}{*}{ Depression } & No & 93353 & 37.5 & 1 & & & 1 & & \\
\hline & Yes & 6115 & 47.2 & 1.40 & (1.33 to 1.48$)$ & $<0.001$ & 1.27 & (1.20 to 1.34$)$ & $<0.001$ \\
\hline \multirow[t]{2}{*}{ Osteoarthritis } & No & 87749 & 37.9 & 1 & & & 1 & & \\
\hline & Yes & 11719 & 39.7 & 1.10 & (1.06 to 1.15$)$ & $<0.001$ & 1.08 & (1.04 to 1.13 ) & $<0.001$ \\
\hline \multirow[t]{2}{*}{ Other joint disorder } & No & 95070 & 38.1 & 1 & & & 1 & & \\
\hline & Yes & 4398 & 38.6 & 1.02 & (0.96 to 1.08$)$ & 0.597 & 0.97 & (0.91 to 1.03 ) & 0.313 \\
\hline
\end{tabular}

*The multiply-adjusted model presented in table 3 contains variables included in table 2 except for the number of comorbidities, and additionally contains the individual types of comorbidities.

†Thus, variables included in the model above are: age group, years, gender, ethnic group, Townsend Deprivation Index, quintiles, household Income, GBP, occupation category, highest level of education (ISCED), country of birth, by income level, UK country of residence, BMI (categorical), smoking status, alcohol units per week (categorical), weekly physical activity, number of antihypertensive medications, family history of CVD, diabetes, arrhythmia (afib/flutter), asthma or COPD, migraines, epilepsy, anxiety, depression, osteoarthritis, other joint disorder, ever screened for bowel cancer. Afib/flutter: atrial fibrillation or atrial flutter.

BMI, body mass index; COPD, chronic obstructive pulmonary disease; CVD, cardiovascular disease; ISCED, International Standard Classification of Education.

(online supplemental table 3), and including UKB participants with serious comorbidities did not alter conclusions drawn from the main analysis.

\section{DISCUSSION}

\section{Principal findings}

Our analysis found that only two out of five treated middle-aged hypertensives were controlled in a high income country (HIC) setting, and revealed that hypertension risk factors and characteristics of lower socioeconomic status were inversely associated hypertension control. We also found that having comorbidities was positively associated with hypertension control, including comorbidities not linked with increased CVD risk.

\section{Strengths and weaknesses of the study}

This is one of the largest population-based analyses of hypertension control in middle-aged adults, and has used comprehensive sociodemographic and medical history data available from the UKB to investigate topics of emerging public health priority (performance of hypertension control in the ageing population and the role of comorbidities). That said, our study has several notable limitations. First, we relied on self-reported information on comorbidities and medications. This may have resulted in differential misclassification, even if mitigated by the in-person interview and review of a medication list by a nurse. Second, UKB baseline data are now a decade old and do not directly include information on factors known to be associated with hypertension control such as medication adherence and healthcare utilisation. Third, participation in the UKB was by volunteers for a longitudinal study and required visiting study assessment centres. Studies have reported evidence of healthy volunteer selection bias and limitations in national representativeness of the UKB study population thus our prevalence 
estimates should be interpreted with this in mind. More specifically, UKB participants have been found to differ from UK nationally representative surveys with respect to several socioeconomic (eg, more liked to be educated), lifestyle and clinical characteristics (eg, less likely to be obese). ${ }^{4}$ Our estimated prevalence of hypertension control may thus not accurately reflect prevalence in the UK's general population aged 40-69 years, and might be anticipated to overestimate this prevalence. While not nationally representative, UKB is a population-based study with a large number of participants who have heterogeneous exposure levels that are assessed with high internal validity. As such, UKB is a suitable resource for providing valid inferences of exposure-outcome associations that are generalisable to other populations, ${ }^{4}$ and for our research objective to identify factors associated with hypertension control.

\section{Prevalence: comparison with other studies and meaning of study findings}

Comparisons between studies of hypertension control prevalence rates are limited by differing age groups reported, noting that hypertension control tends to be lower among older adults compared with younger adults treated for hypertension. Nonetheless, our estimate of hypertension control is comparable with those reported in multicountry studies during UKB's recruitment period: a $40.7 \%$ hypertension control (defined similarly) average among HICs adults aged 35-70 years enrolled 2003-2009 was reported in the PURE (Prospective Urban Rural Epidemiology) study ${ }^{5}$; a systemic review of populationbased studies from 90 countries reported hypertension control proportions of $38.6 \%$ (95\% CI $25.5 \%$ to $51.6 \%$ ) in 2000 and $50.4 \%$ (95\% CI $44.4 \%$ to $56.4 \%$ ) in 2010 for HIC adults aged 18 +years in. ${ }^{23}$ Our estimates are lower than those from Health Survey England (HSE), which in 2008 reported hypertension control prevalence of $58.7 \%$ for ages $45-54$ years and $57.5 \%$ for ages $65-74$ years. HSE reports also indicate an improvement over time in hypertension control prevalence, with 2018 estimates of $63.9 \%$ for ages $45-54$ years for ages $55-64$ years, $54.6 \%$ and $67.7 \%$ for ages $65-74$ years. This discrepancy with our estimates may be due to a combination of differences in age-group cut-offs for estimates reported, differences in how hypertension was defined (HSE did not include self-reported hypertension), and that UKB is not nationally representative. ${ }^{14}$ This notwithstanding, a recent Lancet publication describing trends in hypertension control (employing nationally representative surveys) in 12 HICs found that improvement in hypertension control rates over time has plateaud and that UK's hypertension control performance was poorer than for the US, Germany and Canada. ${ }^{24}$ These figures highlight the continued gaps and continued need for identifying factors associated with control (or lack thereof) that might inform healthcare services improvement efforts.

The nature of these efforts would need to be informed by updated analyses that include operational data on the design of healthcare delivery, process measures for compliance with clinical guidelines and patient adherence with prescribed medicines. While we applied the BP target of 140/90 mm $\mathrm{Hg}$ consistent with clinical guidelines in practice during UKB's recruitment period (NICE 2006), studies have now demonstrated CVD benefit of reducing systolic BP below $120 \mathrm{~mm} \mathrm{Hg}{ }^{25}$ That said, we recognise that the $140 / 90 \mathrm{~mm} \mathrm{Hg}$ threshold used did not distinguish between types of hypertension such as isolated systolic hypertension, and was lower than the practice guidance linked to pay-for-performance reimbursement in 2006. The UK's General Medical Services 2006/2007 contract contained the indicator: 'The percentage of patients with hypertension in whom the last $\mathrm{BP}$ (measured in the previous 9 months) is $\leq 150 / 90 \mathrm{~mm} \mathrm{Hg} \cdot{ }^{26}$ It is for this reason that we included additional analysis using the less stringent $<160 / 100 \mathrm{~mm} \mathrm{Hg}$ threshold for control. With this threshold, a fifth of treated hypertensives were uncontrolled and the associations observed were similar to those in our primary analysis with the exception of gender (for which there was no statistically significant difference in control between men and women).

\section{Associations: comparison with other studies and meaning of study findings}

The relationships we observed between hypertension control and hypertension risk factors such as age, obesity, black ethnicity and alcohol use are consistent with results from previous studies in the $\mathrm{UK}^{727}$ and in other HICs. ${ }^{8}{ }^{29}$ Contributors to poorer control among older adults include increasing vascular stiffness with age, the possible reluctance of providers to intensify medications, and barriers associated with polypharmacy. ${ }^{8}$ Reasons for poorer control in Black people include higher prevalence of resistant hypertension ${ }^{30}$ and structural factors perhaps not well captured by the variables included in our models (eg, neighbourhood deprivation). Lower socioeconomic status has also been linked with poorer hypertension control, ${ }^{31}$ possibly due to a combination of less access to care (eg, less flexible employment situation, longer distance to travel), differential treatment and/ or poorer quality of services, lower health literacy, and more chronic stress. Differences in the odds of hypertension control between England, Scotland and Wales are likely due to regional differences in lifestyle behaviour or healthcare utilisation patterns not accounted for.

To explore the possibility of collider bias introduced by conditioning our analysis on treatment, we performed multivariable logistic regression for the same correlates for hypertension control among all hypertensives (treated and untreated). Results of this analysis were similar to our main analysis results (among treated hypertensives), thus did not support a collider effect by treatment, but we cannot rule this out as a function of selection into UKB.

With regards to comorbidities, our findings are consistent other studies. ${ }^{727}$ In a cross-sectional analysis of UK primary care data of 31676 adults in a single London borough diagnosed with hypertension, Sarkar et al found 
that the number of comorbidities was the strongest predictor of systolic BP and that systolic BP was lower with multimorbidity regardless of the type of comorbidity (including diabetes). ${ }^{7}$ Our analysis expands on these findings by covering a larger geographic area and including a larger sample size and additional explanatory variables.

Hypertensives with comorbidities linked to CVD risk may be better controlled due to providers appropriately managing them more aggressively. ${ }^{8}$ This hypothesis is supported by our finding that smokers and those have migraines are more likely to be controlled, and that a higher percentage of participants with CVD risk factors were on $\geq 3$ antihypertensives (online supplemental table $1)$. There are several possible explanations for the association between hypertension control and comorbidities that are not linked to CVD with respect to pathophysiology, risk factor profile, or management pathway (ie, discordant comorbidities). A leading explanation is the confounding effect of frequent healthcare utilisation, which has been associated with higher hypertension control. ${ }^{8}$ This might happen through exposure to health promotion and medication adherence counselling by providers. It could also be through opportunistic BP screening such that those with comorbidities are diagnosed at an earlier stage of hypertension (with corresponding lower BP).

\section{Unanswered questions and future research}

More studies are needed to investigate the mechanisms underlying the associations between hypertension control and discordant comorbidities, as well as to understand challenges faced by groups with lower odds of hypertension control. Better performance with hypertension control would be expected to reduce CVD-related deaths, but could also potentially lower mortality in the ongoing COVID-19 pandemic, given that hypertension has been linked with poorer outcomes in the setting of COVID-19 infection. $^{32}$

\section{CONCLUSIONS}

In one of the largest population-based analyses in middleaged adults, the majority of individuals treated for hypertension were not controlled. Older, black and lowerincome hypertensives were less likely to be controlled, while those with multimorbidity and at increased CVD risk were more likely to be controlled. More research is needed to understand barriers to hypertension control, and the mechanisms underlying the association between hypertension control and comorbidities not linked with increased CVD risk.

\section{Twitter Neo Tapela @neotapela}

Acknowledgements We are grateful to UK Biobank participants and the study team for making the data available.

Contributors The corresponding author (NT) attests that all listed authors meet authorship criteria. NT designed the study, advised on statistical aspects, interpreted the data and drafted the manuscript. DJH contributed to study design, advised on statistical analysis and interpretation, and contributed to revision of the manuscript. JC performed the statistical analysis, assisted by LC. All authors (NT, $\mathrm{JC}, \mathrm{LC}, \mathrm{IT}, \mathrm{KR}$ and DJH) reviewed the manuscript and approved the final version submitted for publication.

Funding The UK Biobank was supported by the Wellcome Trust, Medical Research Council, Department of Health, Scottish government and Northwest Regional Development Agency. It has also received funding from the Welsh Assembly government and British Heart Foundation. This analysis was supported by the Nuffield Department of Population Health, Oxford University.

\section{Competing interests None declared.}

Patient and public involvement statement The analyses here presented are based on existing UK Biobank study data, of typically healthy populations, and the authors were not involved in participant recruitment. To the best of our knowledge, no patients were explicitly engaged in the design or implementation of the UK Biobank study. No patients were asked to advise on interpretation or writing up of these results. Results from UK Biobank are routinely disseminated to study participants via the study website and social media outlets.

Patient consent for publication Not required.

Ethics approval The UK Biobank received ethical approval from the North West Multicentre Research Ethics Committee (REC reference: 11/NW/03820). This study has been conducted using the UK Biobank resource under application ID 33952.

Provenance and peer review Not commissioned; externally peer reviewed.

Data availability statement The data reported in this paper are available via application directly to the UK Biobank, https://www.ukbiobank.ac.uk.

Open access This is an open access article distributed in accordance with the Creative Commons Attribution 4.0 Unported (CC BY 4.0) license, which permits others to copy, redistribute, remix, transform and build upon this work for any purpose, provided the original work is properly cited, a link to the licence is given and indication of whether changes were made. See: https://creativecommons.org/ licenses/by/4.0/.

\section{ORCID iD}

Neo Tapela http://orcid.org/0000-0002-2048-3973

\section{REFERENCES}

1 Mills KT, Stefanescu A, He J. The global epidemiology of hypertension. Nat Rev Nephrol 2020;16:223-37.

2 World Health Organization. A global brief on hypertension: silent killer, global public health crisis. WHO global brief: Geneva, Switzerland, 2013.

3 Chobanian AV, Bakris GL, Black HR, et al. Seventh report of the joint National Committee on prevention, detection, evaluation, and treatment of high blood pressure. Hypertension 2003;42:1206-52.

4 Ettehad D, Emdin CA, Kiran A, et al. Blood pressure lowering for prevention of cardiovascular disease and death: a systematic review and meta-analysis. Lancet 2016;387:957-67.

5 Chow CK, Teo KK, Rangarajan S, et al. Prevalence, awareness, treatment, and control of hypertension in rural and urban communities in high-, middle-, and low-income countries. JAMA 2013;310:959.

6 Tapela NM, Clifton L, Tshisimogo G, et al. Prevalence and determinants of hypertension awareness, treatment, and control in Botswana: a nationally representative population-based survey. Int $J$ Hypertens 2020;2020:1-12.

7 Sarkar C, Dodhia H, Crompton J, et al. Hypertension: a crosssectional study of the role of multimorbidity in blood pressure control. BMC Fam Pract 2015;16:98.

8 Egan BM, Li J, Shatat IF, et al. Closing the gap in hypertension control between younger and older adults. Circulation 2014;129:2052-61.

9 Egan BM, Zhao Y, Axon RN. Us trends in prevalence, awareness, treatment, and control of hypertension, 1988-2008. JAMA 2010;303:2043-50.

10 Barnett K, Mercer SW, Norbury M, et al. Epidemiology of multimorbidity and implications for health care, research, and medical education: a cross-sectional study. Lancet 2012;380:37-43.

11 Cassell A, Edwards D, Harshfield A, et al. The epidemiology of multimorbidity in primary care: a retrospective cohort study. $\mathrm{Br} \mathrm{J}$ Gen Pract 2018;68:e245-51.

12 Zemedikun DT, Gray LJ, Khunti K, et al. Patterns of multimorbidity in middle-aged and older adults: an analysis of the UK Biobank data. Mayo Clin Proc 2018;93:857-66. 
13 Paulsen MS. Multimorbidity and blood pressure control in 37651 hypertensive. J Am Hear Assoc 2012;2:e004531.

14 Fry A, Littlejohns TJ, Sudlow C, et al. Comparison of sociodemographic and health-related characteristics of UK Biobank participants with those of the general population. Am J Epidemiol 2017;186:1026-34.

15 NCD Risk Factor Collaboration (NCD-RisC). Worldwide trends in blood pressure from 1975 to 2015 : a pooled analysis of 1479 population-based measurement studies with 19.1 million participants. Lancet 2017;389:37-55.

16 Pickering TG, Hall JE, Appel LJ, et al. Recommendations for blood pressure measurement in humans and experimental animals. Circulation 2005;111:697-716.

17 World Health Organisation. Introduction to drug utilization research. Geneva, Switzerland, 2003.

18 Nevado-Holgado AJ, Kim C-H, Winchester L, et al. Commonly prescribed drugs associate with cognitive function: a cross-sectional study in UK Biobank. BMJ Open 2016;6:e012177.

19 Craig CL, Marshall AL, Sjöström M, Sjo M, et al. International physical activity questionnaire: 12-country reliability and validity. Med Sci Sports Exerc 2003;35:1381-95.

20 Yousaf S, Bonsall A. Uk Townsend deprivation scores from 2011 census data. UK Data Service, 2017.

21 Tran J, Norton R, Conrad N, et al. Patterns and temporal trends of comorbidity among adult patients with incident cardiovascular disease in the UK between 2000 and 2014: a population-based cohort study. PLoS Med 2018;15:e1002513-23.

$22 \mathrm{R}$ foundation for statistical computing. A language and environment for statistical computing. Vienna, Austria: R foundation for statistical computing, 2019. www.R-project ORG
23 Mills KT, Bundy JD, Kelly TN, et al. Global disparities of hypertension prevalence and control: a systematic analysis of population-based studies from 90 countries. Circulation 2016;134:441-50.

24 NCD Risk Factor Collaboration (NCD-RisC). Long-term and recent trends in hypertension awareness, treatment, and control in 12 high-income countries: an analysis of 123 nationally representative surveys. Lancet 2019;394:639-51.

25 Still CH, Rodriguez CJ, Wright JT, et al. Clinical outcomes by race and ethnicity in the systolic blood pressure intervention trial (sprint): a randomized clinical trial. Am J Hypertens 2018;31:97-107.

26 NHS. Revisions to the GMS contract 2006 / 07 delivering investment in general practice 2006 .

27 Mathur R, Hull SA, Badrick E, et al. Cardiovascular multimorbidity: the effect of ethnicity on prevalence and risk factor management. $\mathrm{Br}$ $J$ Gen Pract 2011;61:e262-70.

28 Beilin LJ, Puddey IB, Alcohol PIB. Alcohol and hypertension: an update. Hypertension 2006;47:1035-8.

29 Ostchega Y, Zhang G, Hughes JP, et al. Factors associated with hypertension control in US adults using 2017 ACC/AHA guidelines: National health and nutrition examination survey 1999-2016. Am J Hypertens 2018;31:886-94.

30 Carnethon MR, Pu J, Howard G, et al. Cardiovascular health in African Americans: a scientific statement from the American heart association. Circulation 2017;136:e393-423.

31 Shahu A, Herrin J, Dhruva SS. Disparities in socioeconomic context and association with blood. JAHA 2019.

32 Yang J, Zheng Y, Gou X, et al. Prevalence of comorbidities and its effects in patients infected with SARS-CoV-2: a systematic review and meta-analysis. Int J Infect Dis 2020;94:91-5. 